\title{
Is the reliable prediction of individual earthquakes a realistic scientific goal?
}

IAN MAIN

The recent earthquake in Colombia (Fig. 1) has once again illustrated to the general public the inability of science to predict such natural catastrophes. Despite the significant global effort that has gone into the investigation of the nucleation process of earthquakes, such events still seem to strike suddenly and without obvious warning. Not all natural catastrophes are so apparently unpredictable, however.

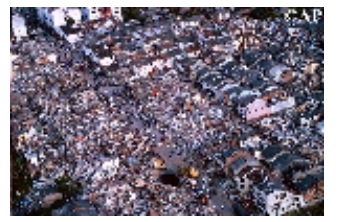
Figure 1 Devastation caused by the recent
earthquake in Colombia.

High resolution image and legend (359k)

For example, the explosive eruption of Mount St Helens in 1980 was preceded by visible ground deformation of up to 1 metre per day, by eruptions of gas and steam, and by thousands of small earthquakes, culminating in the magnitude 5 event that finally breached the carapace. In this example, nearly two decades ago now, the general public had been given official warning of the likelihood of such an event, on a timescale of a few months. So, if other sudden onset natural disasters can be predicted to some degree, what is special about earthquakes? Why have no unambiguous, reliable precursors been observed, as they commonly are in laboratory tests (see, for example, Fig. 2)? In the absence of reliable, accurate prediction methods, what should we do instead? How far should we go in even trying to predict earthquakes?

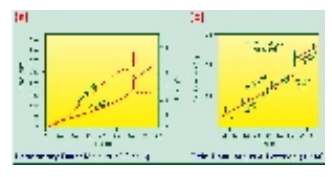

Figure 2 Comparison of laboratory 21 and field $\underline{22}$ measurements of precursory strain (solid lines).

High resolution image and legend (100k)

The idea that science cannot predict everything is not new; it dates back to the 1755 Great Lisbon earthquake, which shattered contemporary European belief in a benign, predictable Universe ${ }^{1}$. In the eighteenth century 'Age of Reason', the picture of a predictable Universe ${ }^{1}$ was based on the spectacular success of linear mathematics, such as Newton's theory of gravitation. The history of science during this century has to some extent echoed this earlier debate. Theories from the earlier part of the century, such as Einstein's relativity, and the development of quantum mechanics, were found to be spectacularly, even terrifyingly, successful when tested against experiment and observation. Such success was mirrored in the increasing faith that the general public placed in science. However, the century is closing with the gradual realization by both practitioners and the general public that we should not expect scientific predictions to be infallible. Even simple nonlinear systems can exhibit 'chaotic' behaviour, whereas more 'complex' nonlinear systems, with lots of interacting elements, can produce remarkable statistical stability while retaining an inherently random (if not completely chaotic) component $\stackrel{2}{2}$. The null hypothesis to be disproved is not that earthquakes are predictable, but that they are not.

The question to be addressed in this debate is whether the accurate, reliable prediction of individual earthquakes is a realistic scientific goal, and, if not, how far should we go in attempting to assess the predictability of the 
earthquake generation process? Recent research and observation have shown that the process of seismogenesis is not completely random - earthquakes tend to be localized in space, primarily on plate boundaries, and seem to be clustered in time more than would be expected for a random process. The scale-invariant nature of fault morphology, the earthquake frequencymagnitude distribution, the spatiotemporal clustering of earthquakes, the relatively constant dynamic stress drop, and the apparent ease with which earthquakes can be triggered by small perturbations in stress are all testament to a degree of determinism and predictability in the properties of earthquake populations ${ }^{3.4}$. The debate here centres on the prediction of individual events.

For the purposes of this debate, we define a sliding scale of earthquake 'prediction' as follows.

1. Time-independent hazard. We assume that earthquakes are a random (Poisson) process in time, and use past locations of earthquakes, active faults, geological recurrence times and/or fault slip rates from plate tectonic or satellite data to constrain the future longterm seismic hazard 5 . We then calculate the likely occurrence of ground-shaking from a combination of source magnitude probability with path and site effects, and include a calculation of the associated errors. Such calculations can also be used in building design and planning of land use, and for the estimation of earthquake insurance.

2. Time-dependent hazard. Here we accept a degree of predictability in the process, in that the seismic hazard varies with time. We might include linear theories, where the hazard increases after the last previous event $\underline{-}$, or the idea of a 'characteristic earthquake' with a relatively similar magnitude, location and approximate repeat time predicted from the geological dating of previous events $\underline{\underline{I}}$. Surprisingly, the tendency of earthquakes to cluster in space and time include the possibility of a seismic hazard that actually decreases with time ${ }^{8}$. This would allow the refinement of hazard to include the time and duration of a building's use as a variable in calculating the seismic risk.

3. Earthquake forecasting. Here we would try to predict some of the features of an impending earthquake, usually on the basis of the observation of a precursory signal. The prediction would still be probabilistic, in the sense that the precise magnitude, time and location might not be given precisely or reliably, but that there is some physical connection above the level of chance between the observation of a precursor and the subsequent event. Forecasting would also have to include a precise statement of the probabilities and errors involved, and would have to demonstrate more predictability than the clustering referred to in time-dependent hazard. The practical utility of this would be to enable the relevant authorities to prepare for an impending event on a timescale of months to weeks. Practical difficulties include identifying reliable, unambiguous precursors $\frac{9-11}{}$, and the acceptance of an inherent proportion of missed events or false alarms, involving evacuation for up to several months at a time, resulting in a loss of public confidence.

4. Deterministic prediction. Earthquakes are inherently predictable. We can reliably know in advance their location (latitude, longitude and depth), magnitude, and time of occurrence, all within narrow limits (again above the level of chance), so that a planned evacuation can take place.

Time-independent hazard has now been standard practice for three decades, atthough new information from geological and satellite data is increasingly being used as a constraint. In contrast, few seismologists would argue that deterministic prediction as defined above is a reasonable goal in the medium 
term if not for ever $\frac{12}{}$. In the USA, the emphasis has long been shifted to a better fundamental understanding of the earthquake process, and on an improved calculation of the seismic hazard, apart from an unsuccessful attempt to monitor precursors to an earthquake near Parkfield, California, which failed to materialize on time. In Japan, particularly in the aftermath of the Kobe earthquake in 1995, there is a growing realization that successful earthquake prediction might not be realistic $\frac{13}{}$. In China, thirty false alarms have brought power lines and business operations to a standstill in the past three years, leading to recent government plans to clamp down on unofficial 'predictions' $\underline{14}$.

So, if we cannot predict individual earthquakes reliably and accurately with

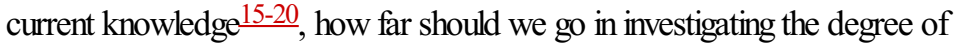
predictability that might exist?

\section{Ian Main}

Department of Geology and Geophysics, University of Edinburgh, Edinburgh, UK

\section{References}

1. Voltaire, Candide (Penguin, London, 1997, first published 1759).

2. Bak, P. How Nature Works: The Science of Self-organised Criticality (Oxford Univ. Press, 1997).

3. Turcotte, D.L. Fractals and Chaos in Geology and Geophysics (Cambridge Univ. Press, 1991).

4. Main, I., Statistical physics, seismogenesis and seismic hazard, Rev. Geophys. 34, 433-462 (1996).

5. Reiter, L. Earthquake Hazard Analysis (Columbia Univ. Press, New York, 1991).

6. Shimazaki, K. \& Nakata, T., Time-predictable recurrence model for large earthquakes, Geophys. Res. Lett. 7, 279-283 (1980).

7. Schwartz, D.P. \& Coppersmith, K.J., Fault behavior and characteristic earthquakes: Examples from the Wasatch and San Andreas fault systems, J. Geophys. Res. 89, 5681-5696 (1984).

8. Davis, P.M., Jackson, D.D. \& Kagan, Y.Y., The longer its been since the last earthquake, the longer the expected time till the next?, Bull. Seism. Soc. Am. 79, 1439-1456 (1989).

9. Wyss, M., Second round of evaluation of proposed earthquake precursors, Pure Appl. Geophys. 149, 3-16 (1991).

10. Campbell, W.H. A misuse of public funds: $U N$ support for geomagnetic forecasting of earthquakes and meteorological disasters, Eos Trans. Am. Geophys. Union 79, 463-465 (1998).

11. Schol, C.H. The Mechanics of Earthquakes and Faulting (Cambridge Univ. Press, 1990).

12. Main, I., Earthquakes - Long odds on prediction, Nature 385, 19-20 (1997).

13. Saegusa, A., Japan tries to understand quakes, not predict them, Nature 397, 284 (1999).

14. Saegusa, A., China clamps down on inaccurate warnings, Nature 397. 284 (1999).

15. Macelwane, J.B., Forecasting earthquakes, Bull. Seism. Soc. Am. 36, 1-4 (1946).

16. Turcotte, D.H., Earthquake prediction, A. Rev. Earth Planet. Sci. 19, 263-281 (1991).

17. Sneider, R. \& van Eck, T., Earthquake prediction: a political problem?, Geol. Rdsch. 86, 446-463 (1997).

18. Jordan, T.H., Is the study of earthquakes a basic science?, Seismol. Res. Lett. 68, 259-261 (1997).

19. Evans, R., Asessment of schemes for earthquake prediction: editor's introduction, Geophys. J. Int. 131, 413-420 (1997).

20. Geller, R.J., Earthquake prediction: a critical review, Geophys. J. Int. 131 425-450 (1997).

21. Main, I.G., Sammonds P.R. \& Meredith, P.G., Application of a modified Griffith criterion to the evolution of fractal damage during 
compressional rock failure, Geophys. J. Int. 115, 367-380 (1993).

22. Argus, D. \& Lyzenga, G.A., Site velocities before and after the Loma

Prieta and the Gulf of Alaska earthquakes determined from VLBI,

Geophys. Res. Lett. 21, 333-336 (1994).

Nature@ Macmillan Publishers Ltd 1999 Registered No. 785998 England. 